\title{
Immunogenicity of Polyethylene Glycol (PEG)
}

\author{
R.P. Garay*,1 and J.P. Labaune ${ }^{2}$ \\ ${ }^{I}$ INSERM U999, University Paris-Sud and Hospital Marie Lannelongue, Le Plessis-Robinson, France; \\ ${ }^{2}$ Pharmacologist, Caslano, Switzerland
}

\begin{abstract}
Covalent attachment of polyethylene glycol (PEG) to active proteins (PEGylation technology) successfully generated several FDA-approved compounds, including four blockbusters, which are considered non immunogenic. However, PEG antibodies and intolerance to the infusion were reported in some patients with gout treated with pegloticase, a PEG-uricase recently approved by the FDA (Food and Drug Administration, USA). Therefore, we reviewed the literature concerning immunogenicity of PEG alone or covalently attached to proteins. We consulted databases (Scirus, Pub Med, Cochrane Library, and Science Direct) and the references of selected articles and main journals publishing articles on the subject. Animal studies clearly showed that PEG-uricases and some other PEGylated proteins might elicit antibody formation against PEG. This anti-PEG response can accelerate the clearance of PEGylated proteins. Of major importance is the recent finding of a $22 \%-25 \%$ occurrence of PEG antibodies in healthy blood donors. PEG antibodies may limit therapeutic efficacy and/or reduce tolerance of PEG-asparaginase (PEG-ASNase) in patients with acute lymphoblastic leukemia and of pegloticase in patients with chronic gout, but apparently do not impair hyposensitization of allergic patients with $\mathrm{mPEG-modified} \mathrm{ragweed} \mathrm{extract} \mathrm{and} \mathrm{honey} \mathrm{bee} \mathrm{venom} \mathrm{or} \mathrm{the} \mathrm{response} \mathrm{to} \mathrm{PEG-}$ interferon in patients with hepatitis C. In conclusion, pre-existing or newly developed PEG antibodies may limit therapeutic efficacy and/or reduce tolerance of PEGylated proteins in some patients. The immunogenicity of PEGylated therapeutic agents in clinical use or development deserves to be re-examined by investigating PEG antibodies.
\end{abstract}

Keywords: Gout, immunogenicity, PEGylated proteins, PEGylation, polyethylene glycol, uricase.

\section{INTRODUCTION}

Pegloticase (Krystexxa ${ }^{\circledR}$, Savient Pharmaceuticals, USA) a polyethylene glycol (PEG) conjugate of a porcine-like uricase, was recently approved by the FDA (Food and Drug Administration, USA) for the treatment of chronic gout, refractory or intolerant to conventional therapy [1]. Placebocontrolled, 6-month clinical trials showed that pegloticase, at doses of $8 \mathrm{mg}$ every 2 weeks, induced a significant decrease in plasma uric acid, associated with the dissolution of tophi in $40 \%$ of patients at final visit $(45 \%$ in patients treated for 25 weeks) [2-5]. However, 58\% of the patients were nonresponders (according to the criteria of plasma urate $<360$ $\mu \mathrm{M}$ for $80 \%$ of the time), which correlated with the formation of anti-pegloticase antibodies and intolerance to the infusion (see also [6]). This was a surprising result because PEG-protein conjugates are widely regarded as immunologically safe [7, 8]. Moreover, PEGylation technology successfully generated several FDA-approved compounds which are considered non immunogenic, including four blockbusters (PegIntron ${ }^{\circledR}$, a PEGylated form of interferon- $\alpha 2 \mathrm{~b}$; Pegasys®, a PEGylated form of interferon- $\alpha 2 \mathrm{a}$, both for the treatment of hepatitis C; Neulasta ${ }^{\circledR}$, a PEGylated form of granulocyte colony stimulating factor for the treatment of chemotherapy-induced neutropenia; and Mircera ${ }^{\circledR}$, a PEGylated epoietin- $\beta$ for the treatment of anemia associated with chronic renal failure) [7]. Therefore, we reviewed the literature concerning

*Address correspondence to this author at 46bis, rue du Marechal Gallieni, 91360 Villemoisson-sur-Orge, France; Tel: +33169048034/+33666468487; E-mail: ricardo.garay@orange.fr immunogenicity of PEG alone or covalently attached to proteins.

\section{METHODS}

\section{Documentary Sources and Study Selection}

Studies on immunogenicity of PEG published from 1977 to today. We consulted databases (Scirus, PubMed, Cochrane Library, Science Direct) using "immunogenicity", "PEG", "PEGylated" and "anti-PEG" as key-words. We also consulted the references of the selected articles and main journals publishing articles on the subject.

\section{RESULTS}

\section{Early Studies of PEGylated Protein Immunogenicity}

PEGylation was first described in the 1970s by Abuchowsky, Davies et al. [9, 10] in two key studies investigating immunogenicity of PEGylated bovine serum albumin and PEGylated bovine liver catalase. Their rational was elegant and convincing:

"Good immunogens typically have a rigid, complex surface structure to which antibodies can be made. We rationalized that the covalent attachment of a linear, flexible, uncharged hydrophilic polymer to available but nonessential groups on an enzyme might provide a shell around the enzyme that covers antigenic determinants and, by presenting a flexible, unbranched, hydrophilic surface for inspection by the immune processes, prevent recognition of the interior enzyme as a foreign substance against which an immune response would be provoked. At the same time, the shell would be permeable to the smaller substrates so that enzymatic activity could continue. » 
Rabbit antisera against native and all tested PEGylated proteins, prepared and tested by immunoprecipitation, showed reducing immunogenicity with the increase in $\%$ PEGylation [10]. This was confirmed by the observation that, unless native catalase, PEGcatalase clearance remained unchanged in the long term [10]. Finally, the authors mention that they also tested repetitive injections of PEGuricase with absence of apparent immunological effects and extended blood circulating life [10].

Following the above pioneering studies, the procedure of PEGylation was expanded and developed tremendously to prolongate half-life of active protein and peptide biopharmaceuticals [7, 8]. In most of these studies, immunogenicity was tested against the active protein. In particular, this was the case with the preclinical, proof of concept study of pegloticase, where immunogenicity was tested with anti-uricase antibodies $[10,12]$.

\section{PEG Antibodies in Animal Models}

PEG is generally considered to be non-immunogenic by itself, but the s.c. administration of $5900 \mathrm{kD} \mathrm{PEG}$ to mice was able to elicit a weak and transitory immune response [13] A stronger anti-PEG immune response was found with PEGylated proteins, particularly ovalbumin [13]. The hapten inhibition in the PEG anti-PEG system by PEG $0.3 \mathrm{kD}$ indicated that the antigenic determinant of PEG may be a sequence of 6-7 - $\mathrm{CH} 2 \mathrm{CH} 2 \mathrm{O}$-units [13].

The haptogenic character of PEG depends on its molecular weight, the immunogenicity of the anchoring protein and the presence of adjuvants [13-15]. Tsuji et al. [16] investigated immunogenicity of a purified uricase from Candida utilis, which was modified to varying degrees with monomethoxypolyethylene glycol of different molecular weights. As increasing amounts of PEG were attached to uricase, it showed decreasing ability to elicit anti-uricase antibody production in rabbits. When sufficient polymers were attached, the modified uricase was devoid of the capacity to combine in vivo and in vitro with anti-uricase antibodies, while it was still able to react with antibodies to PEG-uricase conjugate. Antibodies against PEG-uricase conjugates also reacted with PEG modified superoxide dismutase. The authors conclude that the coupling of PEG to uricase resulted in the loss of original antigenicity and immunogenicity, but in the appearance of new antigenicity and immunogenicity which never showed any crossreactions against the native uricase [16].

In mice receiving multiple injections of betaglucuronidase-PEG, IgG antibodies against the native protein and PEG (protein independent) are produced, with similar affinities against the native protein and the conjugate $[17,18]$. Anti-beta-glucuronidase IgM antibodies are also produced which exhibit high affinity against the conjugate, but did not recognize the native protein. The anti-polymer antibodies could also recognize other PEG conjugates.

PEG antibodies were also described in serum from rabbits, obtained after weekly injections of small liposomes containing 20\% PEG- phosphatidyl ethanolamine [19]. Wang et al. [20] found that, irrespective of the presence or absence PEG-coating, a single first dose of liposomes is capable of inducing a strong anti-PEG IgM response. A good correspondence was observed between the amount of IgM associating with both PEGylated and conventional liposomes, concomitant complement activation triggered by those liposomes and the magnitude of accelerated blood clearance against those liposomes [20]. Conversely, development of antibodies against PEG-methioninase did not result in any immunological reaction or decreased activity in monkeys [21], although no attempt was done to discriminate between PEG and methioninase antibodies.

\section{PEG Antibodies in Humans}

In 1984, Richter and Akerblom [14] reported the presence of naturally occurring PEG antibodies in $0.2 \%$ of healthy blood donors and in $3.3 \%$ of untreated allergic patients. During hyposensitization with methoxy PEG(mPEG)-modified ragweed extract and honey bee venom, respectively, PEG antibodies of the IgM isotype were detected in $50 \%$ of the patients directly after the first treatment course [14]. After 2 years of treatment the percentage of patients with such titers declined to $28.5 \%$. The anti-PEG response was considered to be of no clinical significance [14].

Recently, Garratty et al. [22, 23] detected a high occurrence $(22 \%-25 \%)$ of PEG antibodies in 350 healthy blood donors and identified both IgG and IgM. In patients with acute lymphoblastic leukemia treated with PEGasparaginase (PEG-ASNase), the presence of anti-PEG was very closely associated with rapid clearance of PEG-ASNase $[22,23]$.

Ganson et al. [6] investigated immunogenicity of subcutaneous injections of PEG-uricase to 13 patients with gout. In five subjects, plasma uricase activity could not be detected beyond ten days after injection; this was associated with the appearance of relatively low-titer IgM and IgG antibodies against PEG itself rather than the uricase protein.

Hamad et al. [24] reported that highly concentrated nearmonodisperse endotoxin-free PEGs can generate complement activation products in human serum on a time scale of minutes. Tillmann et al. [25] found a high frequency of PEG antibodies in patients with hepatitis C. These PEG antibodies did not lead to impaired response to PEGinterferon.

\section{DISCUSSION}

In contrast to the general assumption that PEG is nonimmunogenic, animal studies clearly showed that some PEGylated proteins can elicit antibody formation against PEG $[13,16,19]$. This anti-PEG response can accelerate the clearance of PEGylated proteins [17, 18, 20]. In humans, PEG antibodies can be produced and may limit therapeutic efficacy and/or reduce tolerance of PEG-ASNase in patients with acute lymphoblastic leukemia [22] and of pegloticase in patients with chronic gout [2-5], but apparently do not impair hyposensitization of allergic patients with mPEG-modified ragweed extract and honey bee venom [14] or the response to PEG-interferon in patients with hepatitis $C[25,26]$.

The binding epitope of anti-PEG has been shown to be 47 repeat ethoxy units $[13,23]$. On the other hand, cyanuric chloride activated $\mathrm{mPEG}$ has one extra active chloride group that can absorb other amino targets in immunological 
reactions [27]. Other linkers, such as succinimidyl carbonate or propionate, do not have this kind of active group.

Of major importance is the recent finding of a $22 \%-25 \%$ occurrence of PEG antibodies in 350 healthy blood donors $[22,23]$, whereas a very low $0.2 \%$ occurrence was reported by Richter and Akerblom [14] in 1984. Armstrong et al. [22] suggested that this increase is most likely due to greater exposure to PEG and PEG-containing compounds in cosmetics, pharmaceuticals and processed food products. These authors recommend that patients should be screened for preexisting anti-PEG and monitored for the development of anti-PEG throughout the course of treatment with any PEG containing agent [22].

Because of the medical importance of gout and the relative success of pegloticase, research efforts should be dedicated to investigate the immunogenicity of other PEGuricases in development, such as pegsiticase [28] and to reduce uricase immunogenicity. Freitas da Silva et al. [29] have obtained a recombinant uricase from Candida sp. pegylated with mPEG-pNP or mPEG-CN. When injected repeatedly in mice for 21 days, the uricase did not induce detectable antibody response. A different approach was used by Tan et al. [30] by encapsulating an uricase from Candida in lipid vesicles. Finally, due to a nonsense codon inserted into the uricase gene, this enzyme is produced as a truncated, 10 aminoacids long, inactive fragment in humans and apes $[31,32]$. Therefore, another approach can be to "reactivate" human uricase, by eliminating nonsense mutations [11].

In conclusion, pre-existing or newly developed PEG antibodies may limit therapeutic efficacy and/or reduce tolerance of PEGylated proteins in some patients. The immunogenicity of PEGylated therapeutic agents in clinical use or development deserves to be re-examined by investigating PEG antibodies.

\section{CONFLICT OF INTEREST}

None.

\section{ABBREVIATIONS}

FDA $=$ Food and Drug Administration

PEG = polyethylene glycol

\section{REFERENCES}

[1] FDA, Food and Drug Administration, Center for Drug Evaluation and Research. Division of Anesthesia, Analgesia, and Rheumatology Products. AAC Briefing Document Krystexxa (Pegloticase). 2009, Jun 16, Available from http://www.fda.gov/ downloads AdvisoryCommittees/Committees MeetingMaterials/ Drugs/ArthritisDrugsAdvisoryCommittee/UCM165714.pdf. Accessed 2010, Jul 7, 2009.

[2] Burns, C.M.; Wortmann, R.L.Gout therapeutics: new drugs for an old disease. Lancet., 2011, 377, 165-177.

[3] Sundy, J.S.; Baraf, H.S.; Becker. M.A.; Edwards, N.L.; GutierrezUrena., S.R.; Treadwell, E.L.; Horowitz, Z.; Yood, R.A.; Maroli, A.; Waltrip, R. Efficacy and safety of intravenous (IV) pegloticase (PGL) in subjects with treatment failure gout (TFG): phase 3 results from GOUT1 and GOUT2 [abstract]. Arthritis Rheum., 2008, 58(Suppl 9), S635.

[4] Sundy, J.S.; Baraf, H.S.; Becker, M.A.; Edwards, N.L.; GutierrezUrena, S.R.; Treadwell, E.L.; Horowitz, Z.; Yood, R.A.; Maroli, A.; Waltrip, R. Efficacy and safety of intravenous pegloticase (PGL) in treatment failure gout (TFG): results from GOUT1 and GOUT2 [abstract] Ann. Rheum. Dis., 2009, 68(Suppl 3), S318.
[5] Reinders, M.K.; Jansen, T.L. New advances in the treatment of gout: review of pegloticase. Ther. Clin. Risk Manag., 2010, 6, 543550 .

[6] Ganson, N.; Kelly, S.; Scarlett, E.; Sundy, J.; Hershfield, M. Control of hyperuricemia in subjects with refractory gout, and induction of antibody against poly(ethylene glycol) (PEG), in a phase I trial of subcutaneous PEGylated urate oxidase. Arthritis Res. Therapy, 2006, 8(1), R12.

[7] Jevsevar, S.; Kunstelj, M.; Porekar, V.G. PEGylation of therapeutic proteins. Biotechnol., 2010, 5, 113-128.

[8] Veronese, F.M.; Pasut, G. PEGylation, successful approach to drug delivery. Drug Discov Today, 2005, 10(21), 1451-1458.

[9] Abuchowski, A.; van Es, T.; Palczuk, N.C.; Davis, F.F. Alteration of immunological properties of bovine serum albumin by covalent attachment of polyethylene glycol. J. Biol. Chem., 1977, 252(11), 3578-3581.

[10] Abuchowski, A.; McCoy, J.R.; Palczuk, N.C.; van Es, T.; Davis, F.F. Effect of covalent attachment of polyethylene glycol on immunogenicity and circulating life of bovine liver catalase. $J$. Biol. Chem., 1977, 252(11), 3582-3586.

[11] Kelly, S.J.; Delnomdedieu, M.; Oliverio, M.I.; Williams, L.D.; Saifer, M.G.; Sherman, M.R.; Coffman, T.M.; Johnson, G.A.; Hershfield, M.S. Diabetes Insipidus in Uricase-Deficient Mice: A model for evaluating therapy with Poly(Ethylene Glycol)-modified uricase. J. Amer. Soc. Nephrol., 2001, 12, 1001-1009.

[12] Sherman, M.R.; Saifer, M.G.P.; Perez-Ruiz, F. PEG-uricase in the management of treatment-resistant gout and hyperuricemia. Advanc. Drug Deliv. Rev., 2008, 60, 59-68.

[13] Richter, A.W.; Akerblom, E. Antibodies against polyethylene glycol produced in animals by immunization with monomethoxy polyethylene glycol modified proteins. Int. Arch. Allergy. Appl. Immunol., 1983, 70, 124-131.

[14] Richter, A.W.; Akerblom, E. Polyethylene glycol reactive antibodies in man: titer distribution in allergic patients treated with monomethoxy polyethylene glycol modified allergens or placebo, and in healthy blood donors. Int. Arch. Allergy. Appl. Immunol., 1984, 74, 36-39.

[15] Caliceti, P.; Schiavon, O.; Veronese, F.M. Immunological Properties of Uricase Conjugated to Neutral Soluble Polymers. Bioconjugate Chem., 2001, 12(4), 515-522.

[16] Tsuji, J.; Hirose, K.; Kasahara, E.; Naitoh, M.; Yamamoto, I Studies on antigenicity of the polyethylene glycol (PEG)-modified uricase. Intl. J. Immunopharmacol., 1985, 7, 725-730.

[17] Cheng, T.L.; Wu, P.Y.; Wu, M.F.; Chern, J.W.; Roffler, S.R. Accelerated clearance of polyethylene glycol-modified proteins by anti-polyethylene glycol IgM. Bioconjug Chem., 1999, 10, 520528.

[18] Cheng, T.L.; Chen, B.M.; Chern, J.W.; Wu, M.F.; Roffler, S.R. Efficient Clearance of Poly(ethylene glycol)Modified Immunoenzyme with Anti-PEG Monoclonal Antibody for Prodrug Cancer Therapy. Bioconjug Chem., 2000, 11(2), 258-266.

[19] Sroda, K.; Rydlewski, J.; Langner, M.; Kozubek A.; Grzybek M.; Sikorski, A.F. Repeated injections of PEG-PE liposomes generate anti-PEG antibodies. Cell Mol Biol Lett., 2005, 10, 37-47.

[20] Wang, X.Y.; Ishida, T.; Kiwada, H. Anti-PEG IgM elicited by injection of liposomes is involved in the enhanced blood clearance of a subsequent dose of PEGylated liposomes. J. Controlled Release., 2007, 119 (2), 236-244.

[21] Yang, Z.; Wang, J.; Lu, Q.; Jinbao, Xu.; Kobayashi, Y.; Takakura, T.; Takimoto, A.; Yoshioka, T.; Lian, C.; Chen, C.; Zhang, D.; Zhang, Y.; Li, S.; Sun, X.; Tan, Y.; Yagi, S.; Eugene, P.F.; Robert, M.H. PEGylation Confers Greatly Extended Half-Life and Attenuated Immunogenicity to Recombinant Methioninase in Primates. Cancer Res., 2004, 64(18), 6673-6678.

[22] Armstrong, J.K.; Hempel, G.; Koling, S.; Chan, l.S.; Fisher, T.; Meiselman, H.J.; Garratty, G. Antibody against poly(ethylene glycol) adversely affects PEG-asparaginase therapy in acute lymphoblastic leukemia patients. Cancer., 2007, 110(1), 103-111.

[23] Garratty, G. Modulating the red cell membrane to produce universal/stealth donor red cells suitable for transfusion. Vox Sanguinis., 2008, 94(2), 87-95.

[24] Hamad, I.; Hunter, A.C.; Szebeni, J.; Moghimi, S.M. Poly(ethylene glycol)s generate complement activation products in human serum through increased alternative pathway turnover and a MASP-2dependent process. Mol. Immunol., 2008, 46 (2), 225-232. 
[25] Tillmann, H.; Ganson, N.J.; Patel, K.; Thompson, A.J.; Abdelmalek, M.; Moody, T.; McHutchison, J. G.; Hershfield, M.S. High prevalence of pre-existing antibodies against polyethylene glycol (PEG) in hepatitis C (HCV) patients which is not associated with impaired response to PEG-Interferon. J. Hepatol., 2010, 52 (Suppl. 1), S129-S129.

[26] Sarvi, F.; Hashemi-Najafabadi, S.; Vasheghani-Farahani, E.; Shojaosadati, S.A. Surface coating of red blood cells with monomethoxy poly(ethylene glycol) activated with two different reagents. Iran J. Chem. Chem. Eng., 2008, 27, 1-9.

[27] Fisher, T.C. PEG-coated red blood cells-simplifying blood transfusion in the new millennium? Immunohematol., 2000, 16, 3748.

[28] 3SBio, 3SBio acquires pegsiticase global rights from EnzymeRx for \$6.25 million. In The Medical News, News-Medical. Net: 2010.
Da Silva Freitas, D.; Spencer, P. J.; Vassao, R.C.; Abrahao-Neto, J. Biochemical and biopharmaceutical properties of PEGylated uricase. Int. J. Pharm., 2010, 387, 215-222.

[30] Tan, Q.Y.; Wang, N.; Yang, H.; Zhang, L.K.; Liu, S.; Chen, L.; Liu, J.; Zhang, L.; Hu, N.N.; Zhao, C.J.; Zhang, J.Q. Characterization, stabilization and activity of uricase loaded in lipid vesicles. Int. J. Pharm., 2010, 384, 165-172.

[31] Wu, X.W.; Lee, C.C.; Muzny, D.M.; Caskey, C.T. Urate oxidase: primary structure and evolutionary implications. Proc. Natl. Acad. Sci. USA., 1989, 86, 9412-9416.

[32] Bomalaski, J.S.; Holtsberg, F.W.; Ensor, C.M.; Clark, M.A. Uricase formulated with polyethylene glycol (uricase-PEG 20): biochemical rationale and preclinical studies. J. Rheumatol., 2002, 29, 1942-1949.

(c) Garay and Labaune; Licensee Bentham Open.

This is an open access article licensed under the terms of the Creative Commons Attribution Non-Commercial License (http://creativecommons.org/licenses/by-nc/3.0/) which permits unrestricted, non-commercial use, distribution and reproduction in any medium, provided the work is properly cited. 